\title{
Local populations facing long-term consequences of nuclear accidents: lessons learnt from Chernobyl and Fukushima
}

\author{
S. Baudé ${ }^{1}$, G. Heriard-Dubreuil ${ }^{1}$, I.-M. Eikelmann ${ }^{2}$, D. Boilley ${ }^{3}$ and T. Schneider ${ }^{4}$ \\ ${ }^{1}$ MUTADIS, Paris, France. \\ 2 Norwegian Radiation Protection Authority (NRPA), Østerås, Norway. \\ 3 Association for Radioactivity Monitoring in Western France (ACRO), Hérouville-Saint-Clair, France. \\ ${ }^{4}$ Nuclear Protection Evaluation Centre (CEPN), Fontenay-aux-Roses, France.
}

\begin{abstract}
After a large-scale nuclear accident, local populations face a high level of complexity, as their day-to-day life is seriously disrupted by the short and long term consequences of the event. Affected populations face numerous decisions related to their daily life and trade-offs in order to cope with a whole range of unfamiliar issues associated with the long-lasting radioactive contamination. This includes the choice to leave, stay or return in the contaminated zone. Feedback of the Chernobyl and Fukushima post-accident situations in Norway and Japan based on the results of the PREPARE European research project brings insights on the complexity of nuclear post-accident situations in modern democracies involving long-lasting contamination. The main goal of the project was to evaluate how and to what extent local populations can access reliable information to protect themselves and participate to collective decisions, as foreseen in the terms of the Aarhus Convention (1998) on public information \& participation of the UNECE (United Economic Commission for Europe). After an accident, individuals and families, professionals, local communities, public authorities and experts have various response paths that are frequently conflicting. An analysis of the societal mechanisms was performed to identify the interactions of the different paths, the role of values in these social mechanisms as well as the impact of public policies on the resilience and social cohesion of local communities and on their capacity to build their own recovery strategies. It demonstrates the importance of a holistic approach that includes all the societal dimensions of the responses to post-accident situations. The capacity of local actors to build their response to the crisis depends on their capacity to build new forms of cooperation among themselves and with other actors and relevant networks.
\end{abstract}

Keywords: European project PREPARE / information / participation / local populations / Fukushima / Chernobyl / Aarhus Convention / long-lasting contamination

\section{Introduction}

Emergency and post-emergency phases of large scale nuclear accidents with radioactive contamination of the environment and goods impact almost all activities of society and lifestyles (in the contaminated areas and beyond) and lead to complex challenges regarding nuclear safety, radiological protection, radioactive waste management...

Recalling that "displacement nearly always generates conditions of severe hardship and suffering for the affected populations", United Nations' Guiding Principles on Internal Displacement give guaranties to the affected persons. In particular, "competent authorities have the primary duty and responsibility to establish conditions, as well as provide the means, which allow internally displaced persons to return voluntarily, in safety and with dignity, to their homes or places of habitual residence, or to resettle voluntarily in another part of the country. Such authorities shall endeavour to facilitate the reintegration of returned or resettled internally displaced persons." On the latter point, the guiding principles stress that "special efforts should be made to ensure the full participation of internally displaced persons in the planning and management of their return or resettlement and reintegration." It should be emphasised that population voluntary remaining or forced to remain in contaminated territories also suffer from the consequences of the pollution and need the same considerations.

Although it is the primary duty of the States to protect their citizen, authorities also have the duty to enable affected residents in contaminated areas to perform their own evaluation of the risks and define their own protection measures. Thus, the UNECE Aarhus Convention (1998) guarantees access to information, public participation in decision-making and access to justice in environmental matters. This Convention devoted to environmental decision-making in general, also specifically addresses crisis situations, stating (article 5.1.c) that: "In the event of any imminent threat to human health or the environment, whether caused by human activities or due to natural causes, all information which could enable the public to take measures to prevent or mitigate harm arising from the threat and is held by a public authority is disseminated immediately and without delay to members of the public who may be affected." 
The studies of PREPARE on information and participation of affected populations investigated the responses to the Chernobyl and Fukushima accidents in Norway and Japan to bring insights on the complexity of nuclear post-accident situations in modern democracies facing long-lasting contamination. The outcomes are grounded on the experience of people directly engaged in these difficult contexts, who presented and discussed their experience during a workshop (Troms $\varnothing$, Norway, 10th to 11th November 2014) gathering Japanese and Norwegian local actors, and PREPARE researchers and experts. PREPARE specifically focused on the populations living in or returning to contaminated areas. Relocated people also face complex situations and suffer from the degradation of their living conditions. Authorities often forget them. To stay or to flee, to come back or to relocate are difficult choices in a no-win situation.

After an accident, individuals and families, professionals, local communities, public authorities and experts have various response paths that are frequently conflicting. For example, local farmers want to resume their activities and consumers avoid contaminated goods. Conflicts occurred even inside families: some members want to leave the contaminated areas whereas others prefer to stay. An analysis of the societal mechanisms in post-accident contexts was performed to identify the interactions between the various response paths and the role of values in these social mechanisms as well as the impact of public policies on the resilience and social cohesion of local communities and on their capacity to build their own recovery strategies. It demonstrates the importance of the societal dimension of the response to post-accident situations, as the capacity of local actors to build their response to the crisis depends on their capacity to build new forms of cooperation among themselves and with other actors and relevant networks. It also shows how public policies, but also a wide range of actors, can support or conversely hinder this societal process of recovery.

\section{Complexity of post-accident situations undermine the efficiency of traditional policies and governance systems}

Nuclear accidents and their consequences severely disrupt the capacity of local actors to fulfil most of their basic needs (safe food and environment, housing, social relations, children education, healthcare...), whether they are living in a contaminated area or relocated. Unlike the trigger of natural catastrophes, the source of this disruption-radioactive pollution-remains persistent over decades, and return to the living conditions that prevailed before the accident is not achievable due to the disruption created by the accident and its long-lasting consequences. After 30 years, the Chernobyl disaster is still affecting the daily life of groups of population in several countries. For affected families, the different economic, environmental, health, social, personal and family issues that arise cannot be addressed separately. They face the postaccident situation as a whole, and have to find their own ways through its irreducible complexity.

Complexity also arises with the disruption of the usual political and social mechanisms of coordination. Whereas authorities are expected to bring support, information and expertise, many decisions and actions remain in the hands of local actors. The spreading of mutual distrust impedes the building of a consistent multilevel societal response. Interest of national authorities may conflict with the protection of local actors. Public authorities are challenged and many economic and social activities are jeopardised. Recovery requires that local people and communities recreate the conditions to access trustworthy and reliable information that is meaningful in their particular context, to assess the situation and to build relevant action. The capacity of local actors to build a response to the crisis, at a personal and community level, also depends on their capacity to build new forms of cooperation among themselves and with other actors as well as to have a grip on the radiological situation prevailing in their own environment.

Authorities, experts, NGOs, professionals and other actors are also confronted with the complexity of a postaccident situation, although unlike local populations they are not living this complexity to the same degree in their personal day-to-day life. Modern organisation of public and private bodies in specialised silos is at odds with tackling the complexity of a post-accident situation. Each silo is only able to tackle a single specific dimension of the whole issue. Coordination mechanisms are set up progressively to deal with this issue although they are not necessarily fully efficient. The structural inability to address the situation in a holistic way may trigger various adverse effects. In addition, some actors try to benefit from the chaotic situation to cheat or gain power. All actors must learn to think and act in a multi-actor, multi-layer and non-linear system of information and action, in which multiple public and private actors from the local to the international level play a role and influence the response to the post-accident situation. New deliberations processes are required to achieve such a goal. Controversies are necessary in a democracy and do not necessarily result in chaos and worsen distrust. The various actors have to define social processes that can, under favourable conditions, enable an assessment of the reliability of the available pieces of information.

Such confrontation is not symmetric: on the one hand, in the spirit of the Aarhus convention, authorities, experts and other knowledgeable persons have the specific duty to separate facts and values, and draw a limit between what seems certain or at least reasonably reliable and what is more uncertain and questionable. In Japan over-reassuring discourses and the failure to acknowledge uncertainties on the impact of low doses have spurred citizen distrust.

On the other hand, the lack of proper responses puts the affected populations at risk of entering a vicious circle of doubts, distrust, isolation and despair, where the social resources for action are destroyed. In such a context, special attention should be placed on the vulnerable people who cannot find or implement a response on their own.

\section{Recovery is a societal process}

Recovery processes after a nuclear accident are above all societal processes that interact with technical, health, radiological protection, and environmental and economic issues. Population rebuilding their lives need specific supports that include expertise and economic, financial and social 
supports to address the multiple issues they are facing. They need new resources for understanding and action, at both individual and collective levels. Above all, freedom of choice of people and communities is a key element.

Recovery is the outcome of the intermingled transition paths of local actors, authorities, experts, professionals and other public or private organisations, who progressively build their own response and take into account (or not) the feedback of their interactions. These paths are non-linear in a postaccident situation characterised by uncertainties, incomplete information and the need for non-specialised actors to protect themselves against radioactive contamination in their day-today life. Experimentation, trial and errors, revision of objectives and strategies are unavoidable. These various paths interact while the post-accident situation unfolds. They can either mutually reinforce or hinder or undermine each other. Transition paths of local actors aim to recreate an overall quality of life in which radiological protection is only one dimension among others. Rebuilding a "life worth living" is their central concern for the long term. In such a context, mourning for the pre-accident situation to which there can be no return is a necessary step.

\section{A necessary evolution of post-accident governance to support societal recovery processes}

A good policy has to preserve both the cohesion of the affected community and individual freedom. Authorities have to support affected populations and preserve public finances. The solutions cannot be uniform but have to be fair... Public policies can influence in a positive or negative way the social cohesion of the affected communities at local, regional and national levels. Democratic values and culture, dignity, truth, honesty, justice, equity, solidarity are cornerstones for individual and collective response paths. Solidarity between directly affected local communities and the national community (and possibly the international community) is a key condition of recovery. Freedom of choice (e.g. to stay or leave, or to come back or not) is a major value. It is necessary to avoid discrimination and to provide equitable support to people who, for their own reasons, do not follow the mainstream.

We can identify three different phases of the post-accident situation, as the diversity of stakes and the complexity of recovery issues unfold over time.

- The first phase is the deployment of public policies aiming at protecting the populations, focussed on health and radiological protection criteria. In this phase, the role of citizens is progressively increasing in the management of the situation. Risk evaluation and protection measures driven by the public bodies should involve experts chosen by the affected population. Direct involvement of citizens in radioactivity measurements has to be encouraged and supported, as early as possible.

- In the second phase, fair decision-making processes are opened to the participation of citizens and stakeholders who refine and adapt public strategies aiming to protect people from radiation and rebuild economically viable, humanly dignified and socially meaningful living conditions. In conflicting situations with dissymmetric power, citizen should benefit from the support of third parties as lawyers, experts...

- The third phase is a transformation of the governance system that takes into account the emergent nature of recovery processes. In this third phase, public policies aim not only to protect citizens but also to enable and support citizens and local communities in building their own life projects.

These phases represent a shift of focus of public authorities' strategies as well as of the goals of citizens and local communities, evolving from a concern of managing risks to a larger perspective of restoring human life quality (which includes risk management but is not limited to it).

Post-accident situations are too complex to be successfully framed, controlled or governed by traditional mechanisms of authority and expertise. Recovery must be recognized as a social process, and cooperation is needed to create favourable conditions for this social process to develop and make progress. There is no one-size-fits-all solution and public policies should accommodate multiple solutions. Public authorities, experts, NGOs, citizen initiatives, professionals, foreign institutions and other actors can support (or conversely block) societal recovery dynamic.

Different ways to support these societal recovery dynamics have been identified in the considered cases: ensuring transparency on the situation and its assessment, preserving the latitude of the local actors, safeguarding social cohesion of local communities, supporting the initiatives of local actors and professionals, providing tools and processes for bridging the transition paths of the different actors, and making room for pluralistic assessment of the post-accident situation and responses.

\section{Conclusion}

As demonstrated by the experiences of Japanese and Norwegian local actors, nuclear accidents and their consequences confront people with an issue that is of economic, sanitary, environmental, social, ethical, cultural and familial nature. Traditional top-down management or so-called Decide - Announce-Defend (DAD) approaches lead to failures, as this complexity cannot be legitimately addressed in the place of local people or on their behalf. They are the only ones capable of and legitimate in balancing all these dimensions. Nevertheless, local people should not be abandoned. They need financial support and access to expertise and research programs. Authorities should define benchmarks to ensure the protection of the population with a focus on the most vulnerable people. Thus, post-accident situations fundamentally challenge the modern ways of understanding our environment, building decisions, public policies and taking public and private action, which consist of separating issues into different sub-questions that should be addressed by specialised organisations or experts. In addition to specialized analysis, there is a crucial need for an effective coordination between various layers and mechanisms for building a holistic response to a post-accident situation. 
Nuclear accidents and their consequences confront people, institutions and structures with irreducible complexity and force them to imagine new ways of building their understanding of the situation and organising actions. For local actors, this means, building a new life that differs from the life before the accident, whatever their choice - to return or to rebuild their lives in a new place.

Preparation to nuclear accidents is necessary but cannot be reduced to response plans, resources and institutional mechanisms. Social dimensions in preparedness are equally important.

Indeed, in these situations, it is important to acknowledge that recovery processes are not only a matter of management, decisions, standards, resources, infrastructures and expertise but also rely heavily on the capacity of local actors to build new networks, social resources, trustful relations and governance schemes. Recovery is above all made by people, and their capacity to think and act together is as important as their individual capacity of action. In the recovery process, autonomy, resilience, social cohesion, capacity of action and freedom of choice of people and communities are key elements, as well as transparency and openness of institutions.
The deployment of such a social process of recovery cannot be decreed, nor is it guaranteed by the mere reconstruction of favourable economic and material conditions. Various actors like public authorities, experts, NGOs, foreign institutions, can bring support or conversely hinder this social process of recovery. While continuing to fulfil responsibilities of protection of population and restoration of infrastructures, post-accident recovery policies should focus on enabling and supporting local people and local communities that engage this long and costly effort of rebuilding a life that is worth living. In this perspective, the implementation of Public Information and Participation provisions as drawn by the UNECE Aarhus Convention is a major step in enabling civil society engagement in the decisionmaking along the successive phases of accident management and recovery processes. United Nations' Guiding Principles on Internal Displacement should also be acknowledged and applied by authorities.

Acknowledgement. The research leading to these results has received funding from the European Atomic Energy Community Seventh Framework Programme FP7/2012-2013 under grant agreement 323287.

Cite this article as: S. Baudé, G. Heriard-Dubreuil, I.-M. Eikelmann, D. Boilley, T. Schneider. Local populations facing long-term consequences of nuclear accidents: lessons learnt from Chernobyl and Fukushima. Radioprotection 51(HS2), S155-S158 (2016). 